\title{
Adolescent Girls Empowerment Program (AGEP): Adapting the safe spaces model in rural settings
}

Population Council

Follow this and additional works at: https://knowledgecommons.popcouncil.org/departments_sbsr-pgy

Part of the Demography, Population, and Ecology Commons, Family, Life Course, and Society Commons, International Public Health Commons, and the Rural Sociology Commons How does access to this work benefit you? Let us know!

\section{Recommended Citation}

"Adolescent Girls Empowerment Program (AGEP): Adapting the safe spaces model in rural settings," brief. Lusaka: Population Council, 2017. 


\section{ADOLESCENT GIRLS EMPOWERMENT PROGRAM (AGEP): Adapting the Safe Spaces Model in Rural Settings}

\section{INTRODUCTION}

For adolescent girls, key differences exist between growing up in urban versus rural settings. In Zambia, for example, urban settings are more densely populated, have higher HIV prevalence, have higher crime rates, and are areas where girls are more likely to live apart from both parents. In rural settings, girls are more likely to marry earlier, start childbearing early, be out of school, and be illiterate (CSO, MOH, and ICF International 2014). To successfully implement a program in both urban and rural areas, it is likely that key adaptations will have to be made.

The program model of regularly bringing adolescent girls together in groups under the guidance of a female mentor to discuss a variety of topics (often called Safe Spaces) has been used widely in Asia, Latin America, and sub-Saharan Africa. The core components of the Safe Spaces model include: (1) forming girls groups that meet at least once a week over an extended period of time; (2) segmenting the groups by age and life stage (i.e., schooling status or marital status) such that girls can develop strong social networks with their peers; and (3) having a mentor who is a young woman from the community lead and facilitate the group sessions (Austrian and Ghati 2010). The content of the training delivered in Safe Spaces groups varies by program focus and geographic area.

The Adolescent Girls Empowerment Program (AGEP) was implemented with over 10,000 vulnerable adolescent girls aged 10-19 between 2013 and 2016 in five rural and five urban sites in Zambia. Safe Spaces was the core program element in AGEP, and was adapted based on prior programs implemented mainly in urban and periurban areas in East and Southern Africa.

Given the key differences in the living environments and demographic data for adolescent girls in urban as compared to rural areas in Zambia, one key programmatic learning question for AGEP was if the Safe Spaces model could be adapted and successfully implemented in rural settings. This brief focuses on the key adaptations made to the program in rural settings.

\section{ADAPTATIONS}

The main driver for the need for adaptations was the distance the girls live from one another and from any central meeting point. In urban areas, girls typically live in densely populated areas where they are able to reach a central meeting point within a 20-minute walk, on average. Mentors are also able to reach the homes of the girls in their group in a reasonable amount of time. Conversely, it took girls in the rural areas twice as long to walk to their groups, because they live in more sparsely populated areas where any central meeting location-a school, church, clinic-is farther away.

The Population Council conducts research and delivers solutions that improve lives around the world. Big ideas supported by evidence:

It's our model for global change. popcouncil.org

(c) 2017 The Population Council, Inc

This project was funded by UK aid from the UK government.
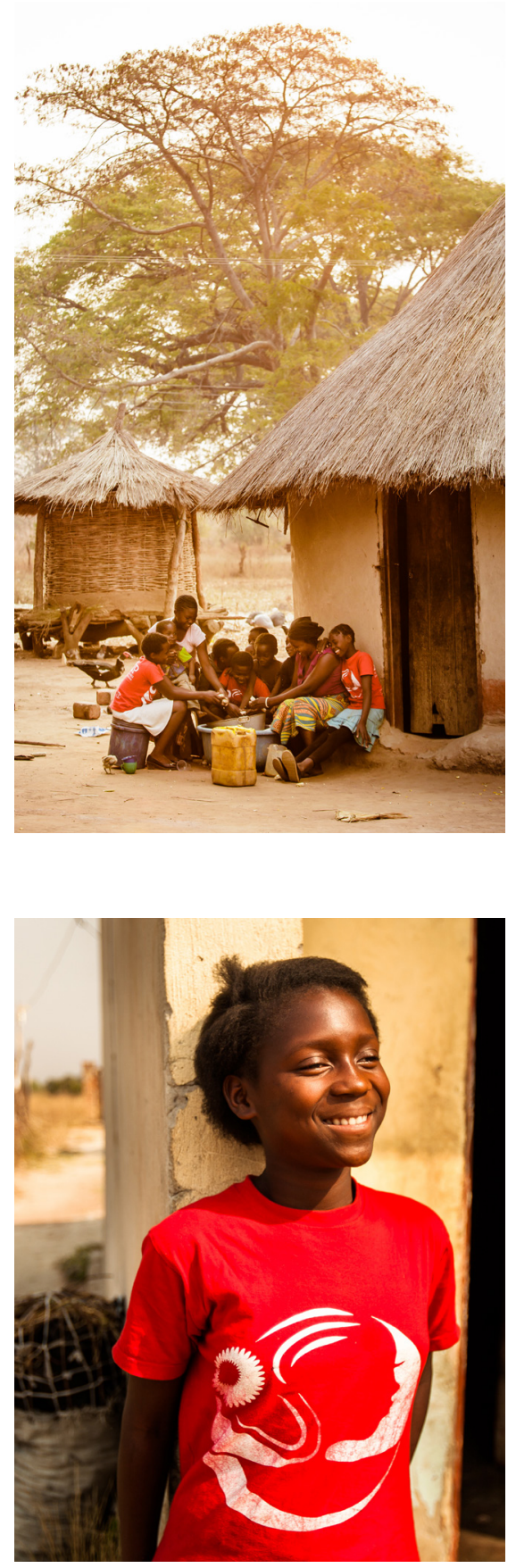

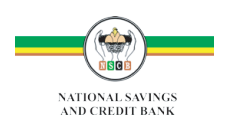

Making Cents 
To address the long distance girls and mentors had to travel to attend Safe Spaces meetings and that mentors had to travel to conduct home visits with the girls in their groups, the following adaptations were made to the Safe Spaces model used in the rural sites of AGEP:

- BICYCLES-Mentors were loaned bicycles so that they could travel to and from the Safe Spaces groups and around the catchment area where their girls lived with greater facility. The mentors were given the bicycles at the end of the program as a token of appreciation.

- MOTORBIKES-Site coordinators (field program staff) were given motorbikes so that they could properly supervise their sites. The AGEP rural sites sometimes covered several thousand square kilometers, such that using a bicycle to get to multiple locations to visit and monitor Safes Spaces groups was not feasible. Motorbikes allowed for proper supervision and support of mentors.

- SMALLER GROUP SIZE-In the rural areas, allowances were made to have smaller groups so that girls did not have to travel farther than necessary to a central point. Therefore, the average group size in rural areas was 10-15 girls, and mentors had 3-4 groups, as compared to urban areas where group sizes were 20-30 girls and mentors each had 1-2 groups.

- SECURITY ESCORTS-The terrain that girls and mentors walked through in the rural areas often included large patches of tall grass near uninhabited areas. Walking through the grass was a security risk, because thieves and sexual predators often hid in the grass, waiting for the girls and mentors to pass. When necessary, the program provided the funds for community members to escort the girls and mentors to their Safe Spaces meetings.

Two additional non-distance-related adaptations were made. One was a curriculum-related adaptation in which case studies and stories that were used to present key lessons from the sessions were offered in both urban and rural versions. For example, in a session from the financial education curriculum, the urban story presents a girl who is making money by assisting at her aunt's hotel, and the rural story presents a girl who is making money by assisting on her aunt's farm.

A second adaptation related to mentor recruitment. In the standard model, mentors were 20 to 30 years old, so they were somewhat older than the girls in their group but not significantly older so that the girls would not feel comfortable opening up. However, in the rural areas, due to lower human resource capacity, the age cap had to be raised in some cases to recruit a large enough number of secondary-school graduates with experience working with young people.

\section{CONCLUSION}

With the adaptations made, the Safe Spaces intervention was successfully implemented in five rural sites in Zambia with over 5,000 girls. Furthermore, attendance in the rural areas was higher on average than in the urban areas (Austrian et al. 2016). One hypothesis for why younger and rural girls were more likely to participate is that there were fewer competing interests, i.e., fewer other programs and social activities were offered that girls could engage in during their free time. Especially in the remote rural areas, AGEP was "the only show in town," and therefore girls were more eager to join and participate. These findings are encouraging and suggest that the Safe Spaces model can work in a diverse range of settings-if the right adaptations are made.

\section{REFERENCES}

Austrian, K. and D. Ghati. 2010. Girl-Centered Program Design: A Toolkit to Develop, Strengthen \& Expand Adolescent Girls Programs. Population Council. www.popcouncil.org/uploads/pdfs/2010PGY_ AdolGirlToolkitComplete.pdf.

Austrian, Karen, Paul C. Hewett, Erica Soler-Hampejsek, Fiammetta Bozzani, Jere R. Behrman, and Jean Digitale. 2016. "Adolescent Girls Empowerment Programme: Research and Evaluation Mid-Term Technical Report." Lusaka, Zambia: Population Council.

Central Statistical Office (CSO) [Zambia], Ministry of Health (MOH) [Zambia], and ICF International. 2014. Zambia Demographic and Health Survey 2013-14.

Rockville, MD.

\section{Population Council, Zambia}

Plot 3670, No. 4

Mwaleshi Road, Olympia Park

Lusaka, Zambia

Tel: +260 211295925

email:info.zambia@popcouncil.org

Photo: John Healey

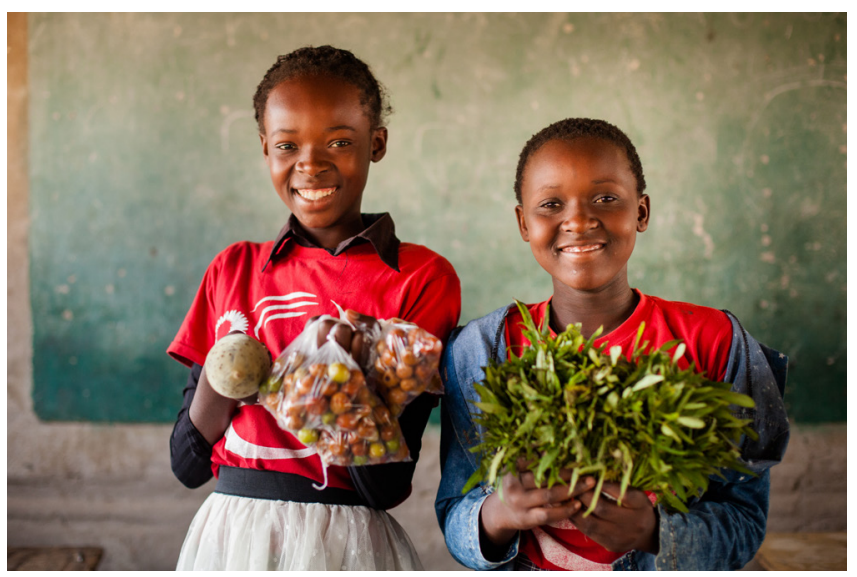

